\title{
La Protesta Mapuche Como Proceso \\ INTERACTIVO: \\ ESPACIOS Y DiNÁMICAS DEL CONFLICTO EN EL RETORNO DE PIÑERA
}

\section{Nicolás Rojas Pedemonte ${ }^{1}$ \\ Diego Gálvez ${ }^{2}$}

\section{Resumen}

Este artículo analiza el curso de la protesta mapuche durante el año 2018. A partir de una revisión exhaustiva de prensa, tanto corporativa como independiente (incluidos medios mapuche), los autores describen la magnitud y el tipo de repertorios de protesta desplegados por el movimiento mapuche en su territorio históricamente habitado. Junto con el análisis estadístico descriptivo de las frecuencias y tipos de repertorios, se desarrolla un análisis geoestadístico para identificar territorialmente su distribución y concentración en las provincias de Arauco, Malleco y Cautín. Los autores apuestan por situar la protesta en el escenario político, identificando las causas particulares asociadas a la acción colectiva registrada y los principales hitos del conflicto que la contextualizan. Finalmente, el análisis se concentra en aquellos ciclos de mayor conflictividad y se destaca la interacción entre las medidas gubernamentales concretas de supresión de las protestas y la movilización mapuche. En aquellas coyunturas de mayor conflictividad, se identifica una estrecha relación entre la violencia policial y la violencia política mapuche como fenómeno de (contra)violencia.

${ }^{1}$ Director el Centro Vives de la Universidad Alberto Hurtado.

2 Investigador del Centro Vives de la Universidad Alberto Hurtado. 
Para los activistas y para quienes estudian los movimientos sociales en Chile, el año 2018 posiblemente será recordado por las manifestaciones winkas -chilenas, no mapuches-, en repudio al asesinato de Camilo Catrillanca, ocurrido en la comuna de Ercilla el miércoles 14 de noviembre a manos del "Comando Jungla" de Carabineros. Por primera vez en la capital, la sociedad chilena -masiva y disruptivamente- se manifestaba contra la represión policial del Estado perpetuada contra el Pueblo Mapuche. En este contexto, se desató un ciclo de protestas con masivas marchas en distintas ciudades durante el mes y medio que restaba para culminar el año. Las protestas se iniciaron disruptivamente, esa misma noche, en Quidico -comuna de Tirúa ${ }^{3}$, para propagarse desde allí a las capitales regionales más próximas - Temuco y Concepción- y también a otras más distantes como Iquique y la propia capital chilena. En Santiago, las protestas se iniciaron el jueves 15, conjugándose con demandas medioambientales previamente movilizadas y alcanzando altos niveles de (contra) violencia política y represión policial ${ }^{4}$ : cuatro buses del transporte público de Transantiago, incendiados durante la primera semana ${ }^{5}$, nueve carabineros lesionados ${ }^{6}$ y más de 100 manifestantes detenidos al finalizar el año. Este ciclo de protestas -inédito en la capital desde el retorno a la democracia- representa, sin duda, el principal antecedente del estallido social del año siguiente en la capital, destacando desde entonces la indignación y el rechazo a los abusos como marco

\footnotetext{
${ }^{3}$ https://www.cooperativa.cl/noticias/pais/region-del-biobio/desconocidosincendiaron-una-vivienda-en-la-provincia-de-arauco/2018-11-15/005844.html ${ }^{4}$ https://www.t13.cl/videos/nacional/video-noche-furia-protesta-santiago-muertecatrillanca https://resumen.cl/articulos/asi-se-vivieron-las-jornadas-de-protestas-contrazonas-de-sacrificio-y-asesinato-de-catrillanca-en-distintos-puntos-del-pais 5 https://www.emol.com/noticias/Nacional/2018/11/22/928254/72-en-ochoanos-y-cuatro-en-la-ultima-semana-El-balance-de-los-buses-del-Transantiago-quehan-sido-quemados.html ${ }^{6}$ https://www.publimetro.cl/cl/noticias/2018/12/28/protestas-catrillanca-dejannueve-carabineros-lesionados.html
} 
discursivo. En este artículo, se estudiarán las protestas desarrolladas en territorio mapuche durante el 2018, destacando por sobre todo la conflictividad desatada por el asesinato de Camilo Catrillanca; aunque sin agotar allí la descripción y análisis del año, dado el carácter estructural y permanente del conflicto en aquel territorio.

Dado que los siguientes capítulos de esta publicación abordan la criminalización de la protesta, detallando la judicialización del conflicto y las violaciones a los Derechos Humanos, este estudio se concentra en los hechos de protesta registrados en el territorio mapuche. En específico, estudiaremos las tres principales provincias de la "Gran Araucanía": Arauco, Malleco y Cautín, describiendo los hechos de protestas desde sus repertorios convencionales-pacíficos, hasta aquellos confrontacionales y de violencia política. Reconociendo los sesgos del tratamiento mediático del conflicto (Amolef, 2005; Labrín, 2011), este artículo recurre a una amplia gama de periódicos en línea como fuentes de información, apostando por alcanzar la mayor diversidad y cobertura posible en los territorios estudiados. Expresión de la diversidad ideológica de la muestra es la inclusión de grandes medios o vinculados a medios corporativos -El Mercurio, Soy Chile, La Tercera, Publimetro y Biobío- y también de medios independientes o locales con otra perspectiva y cobertura del conflicto, directamente más crítica o, incluso, afín al movimiento -como Mapuexpress, El Ciudadano, Radio Villa Francia y Werken-. Esta tarea fue realizada con las herramientas de Google, aplicando filtros según sitio web, fecha y palabras claves $^{7}$, utilizando además las herramientas de búsqueda de cada medio de prensa. De esta forma, fue posible abarcar

\footnotetext{
7 El primer filtro se realizó escribiendo el código 'site: [link página web sin el sistema de hipertexto www.]', por ejemplo, 'site: latercera.com' para realizar la búsqueda en el sitio web del periódico La Tercera. El segundo filtro se realizó con la herramienta de búsqueda Google, seleccionando 'intervalo personalizado', año 2018. El tercer filtro se realizó escribiendo la palabra clave inmediatamente después del código 'site: latercera.com' -siguiendo el ejemplo anterior-, las palabras claves utilizadas fueron: Mapuche y las comunas de las provincias estudiadas.
} 
cada hecho noticioso referido al movimiento mapuche, según cada uno de los medios de prensa seleccionados para el periodo de tiempo abarcado por esta investigación. Una vez realizada la búsqueda, se realizó una sistematización de los datos encontrados. Así, se elaboró una base de datos agrupando cada hecho noticioso según las siguientes categorías: Fecha, Fuente, Descripción del hecho, Región, Provincia, Comuna, Localidad, Coordenadas, Repertorios de protesta, Tipo de conflicto, Actor Demandante y Actor Demandado. A continuación, se describen los resultados.

\section{Hechos de protesta en un territorio en conflicto}

El catastro de hechos noticiosos arrojó 238 hechos de protesta ocurridos durante todo el año 2018 en el territorio mapuche, correspondiente a las provincias de Arauco, Malleco y Cautín. De ellos, la gran mayoría se concentró en Cautín, con un 41,1\% del total; mientras que 29,8\% se concentraron en Arauco y 28,9\% en Malleco. A nivel general, según lo ilustra el Gráfico 1, los repertorios de protesta que más se repiten durante el año 2018 fueron las manifestaciones ${ }^{8}$, concentrando un $17,2 \%$ del total de hechos noticiosos; seguido por los daños a maquinaria forestal ${ }^{9}$ con un 16,3\%; y por las acciones discursivas ${ }^{10}$ que representan un $13 \%$. Le siguen de cerca los ataques realizados a viviendas, iglesias o colegios con un 13\% del total; las acciones legales con un $7,9 \%$; y los comunicados ${ }^{11}$ públicos con un $6 \%$ del total. El resto de los hechos noticiosos no representan por sí solos un porcentaje significativo y dicen relación con acciones enmarcadas

\footnotetext{
${ }^{8}$ Marchas, protestas pacíficas en espacios públicos, etc.

${ }^{9}$ Sabotajes que también incluyen ataques incendiarios a otro tipo de empresas, pero mayoritariamente se refiere a daños de maquinaria forestal.

10 Protestas realizadas que involucran una manifestación verbal sobre algún hecho particular.

${ }^{11}$ Hechos de protesta que manifiestan explícitamente la realización de un comunicado público sobre un tema particular, o bien, que demandan
} 
en el ámbito político convencional, las huelgas de hambre ${ }^{12}$, los bloqueos de carretera, las ocupaciones de predios forestales, los enfrentamientos y emboscadas, y las tomas de sedes institucionales, entre otros. Estos últimos repertorios destacan, no por su cuantía, sino por su capacidad disruptiva, es decir, por lograr alterar las rutinas y el orden público.

\section{Gráfico 1: Hechos noticiosos según repertorio de protesta en las tres provincias de estudio}

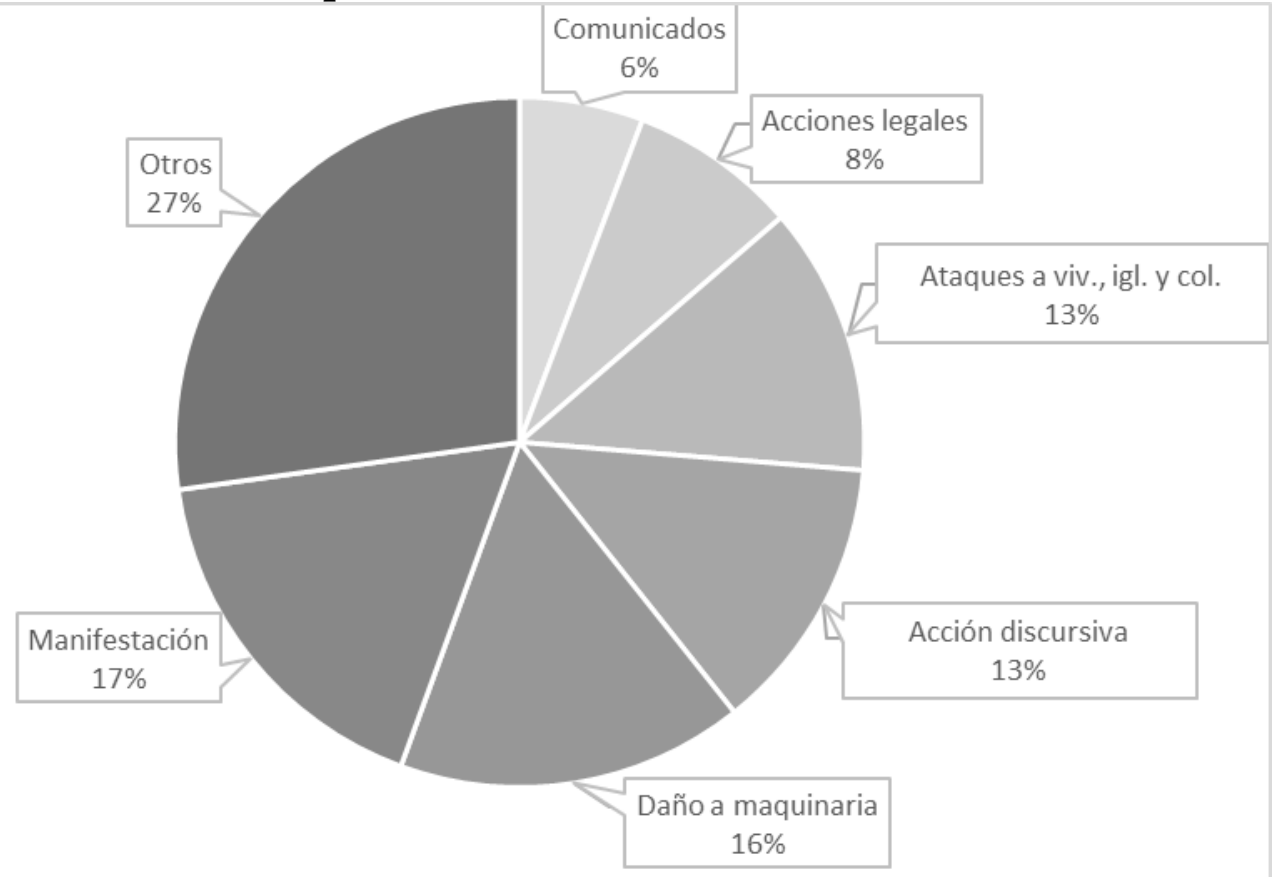

Fuente: Elaboración propia según medios de prensa estudiados

Al revisar la distribución de estos repertorios de protesta a nivel provincial, se evidencia que si bien la provincia de Arauco no

\footnotetext{
12 Si bien las huelgas de hambre no concentran una gran cantidad de hechos, como se verá más adelante, sí tienen un gran impacto mediático y se configura como un hecho coyuntural que refuerza la aparición de otros hechos de protesta.
} 
concentra la mayor parte de la protesta mapuche, sí presenta -como lo ilustra el Gráfico 2- un alto porcentaje de protestas altamente disruptivas y violentas. Los repertorios radicales más recurrentes en esta provincia durante el 2018 fueron los ataques a viviendas (22\%), daño a maquinaria $(20 \%)$, emboscadas $(6 \%)$ y bloqueos de carretera $(5 \%)$. Estas variantes más extremas de la protesta alcanzaron $48 \%$ del total provincial de hechos registrados. Por su parte, las protestas con menor disrupción suman entre sí un porcentaje más bajo $(32 \%)$ : acciones discursivas (11\%), los comunicados (9\%), manifestaciones pacíficas $(6 \%)$ y acciones legales $(6 \%)$.

Gráfico 2: Hechos noticiosos según repertorio de protesta, provincia de Arauco

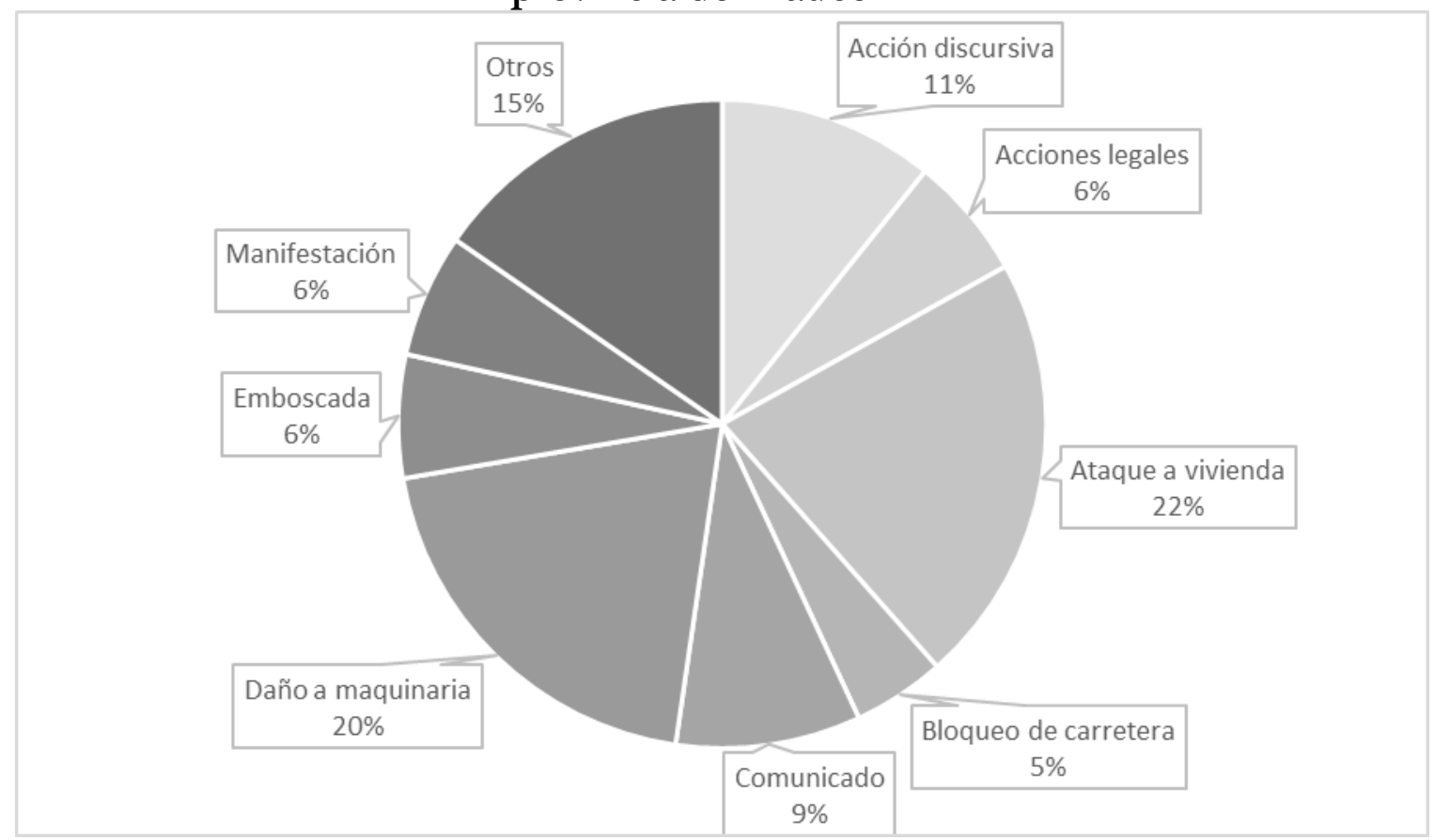

Fuente: Elaboración propia según medios de prensa estudiados 
En Malleco, en cambio, se observa una mayor dispersión de los repertorios. Si bien hay un alto porcentaje de hechos disruptivos relativos a ataques incendiarios o daño a maquinaria (19\%), el resto de los repertorios se distribuyen sin grandes concentraciones, aumentando el porcentaje de protesta con menor disrupción como las acciones discursivas (13\%) y acciones legales (14\%). Los repertorios altamente disruptivos en Malleco solo suman 35\%, trece puntos porcentuales menos que en Arauco, mientras que, a la inversa, la protesta de disrupción baja sube a 39\%, siete puntos porcentuales más que en la provincia costera.

\section{Gráfico 3: Hechos noticiosos según repertorio de protesta, provincia de Malleco}

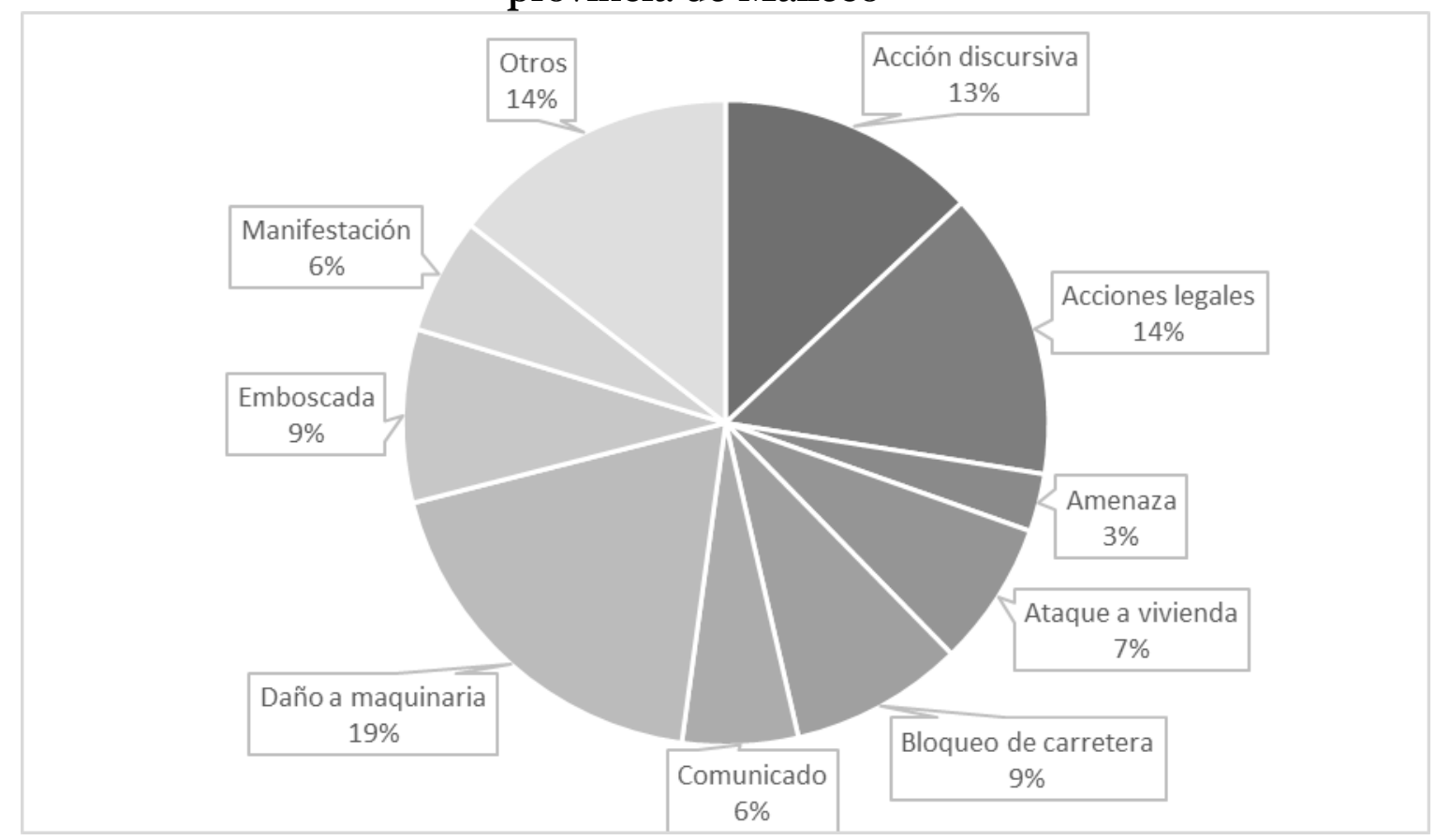

Fuente: Elaboración propia según medios de prensa estudiados 
Por su parte, Cautín, aquella provincia que concentra la mayor parte de la protesta mapuche (41\%), presenta la más alta concentración de hechos de protesta con disrupción baja, como las manifestaciones $(34 \%)$ y acciones discursivas $(16 \%)$. La protesta en esta provincia es mayoritariamente de disrupción baja, 59\% en total. Esto representa $27 \%$ más que Arauco, y 24\% más que Malleco. El porcentaje de hechos de protesta de alta disrupción en Cautín es el más bajo de las tres provincias, alcanzando apenas 19\%: 29 puntos menos que Arauco y $16 \%$ menos que Malleco. Mientras en esta provincia es donde aparecen los ataques a iglesias, el daño a maquinaria, repertorio que anteriormente se encontraba entre los más repetitivos, disminuye significativamente su frecuencia, alcanzando apenas 14\% del total de hechos de protesta, 6 puntos por debajo de Arauco y 5 de Malleco. Este patrón, que muestra cierta coincidencia con los registros de los dos años anteriores, insinúa la existencia de una matriz estructural del conflicto que difiere de aquellas de Arauco y Malleco: mientras en estas provincias el conflicto gira, principalmente, en torno a una matriz productiva extractivista, asociada principalmente a la gran industria maderera, el conflicto en Cautín respondería significativamente a una matriz con resabios coloniales donde, en gran medida, los conflictos son históricos y culturales, y se asocian a la asimétrica relación del Pueblo Mapuche con las acomodadas y conservadoras familias chileno-europeas, la Iglesia Católica y las agencias gubernamentales (Cf. Rojas Pedemonte y Lobos, 2016). Esto último es importante, si se considera que en esta provincia se encuentra la capital regional de La Araucanía, la ciudad de Temuco, lugar donde se concentra la mayor parte de las manifestaciones y marchas. 
Gráfico 4: Hechos noticiosos según repertorio de protesta, provincia de Cautín

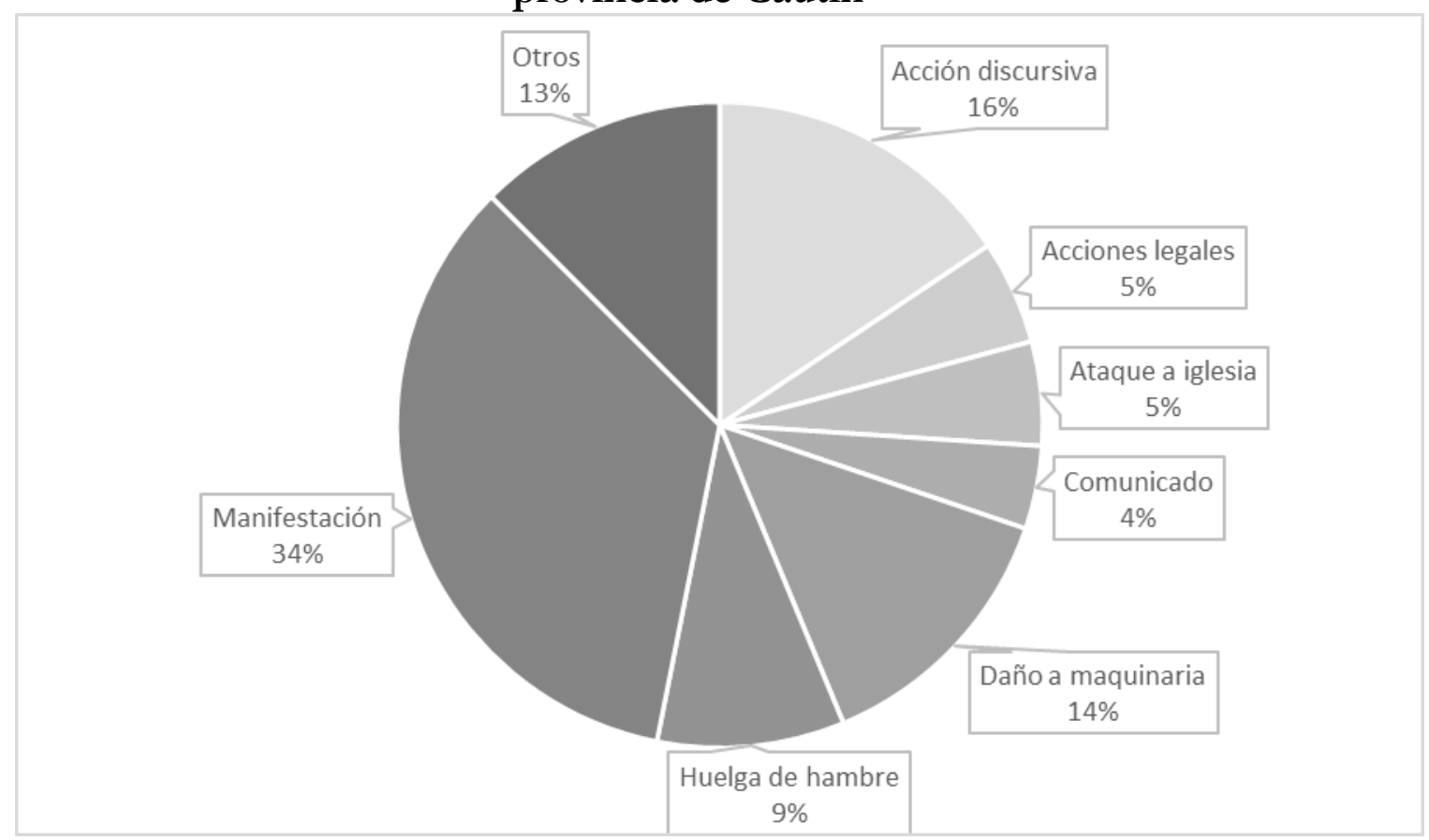

Fuente: Elaboración propia según medios de prensa estudiados

\section{Territorialización del conflicto, la protesta en el espacio}

Es posible hablar de distintas realidades socioterritoriales del conflicto. Con distintas dinámicas, actores, particularidades en sus repertorios, $\mathrm{y}$, ciertamente, contextos políticos y productivos propios. Con el objetivo de visibilizar con mayor detalle estas distintas realidades geográficas del conflicto, identificando la distribución territorial de los hechos de protesta $\mathrm{y}$, por lo tanto, reconociendo sus concentraciones, la Figura 1 muestra los principales focos de protesta identificados durante el año 2018. En ella, se muestran principalmente tres grandes focos. El primero de ellos da cuenta de una alta concentración en el sector rural del territorio que se encuentra entre el pueblo de Tirúa y la 
ciudad de Cañete, a lo largo de la ruta P-70 que une ambos centros urbanos; el segundo de ellos se encuentra en la comuna de Ercilla y Collipulli; y el tercero se concentra fuertemente en la comuna de Temuco y Padre Las Casas, teniendo como punto central la ciudad de Temuco.

Figura 1: Focos de protesta, territorio de estudio
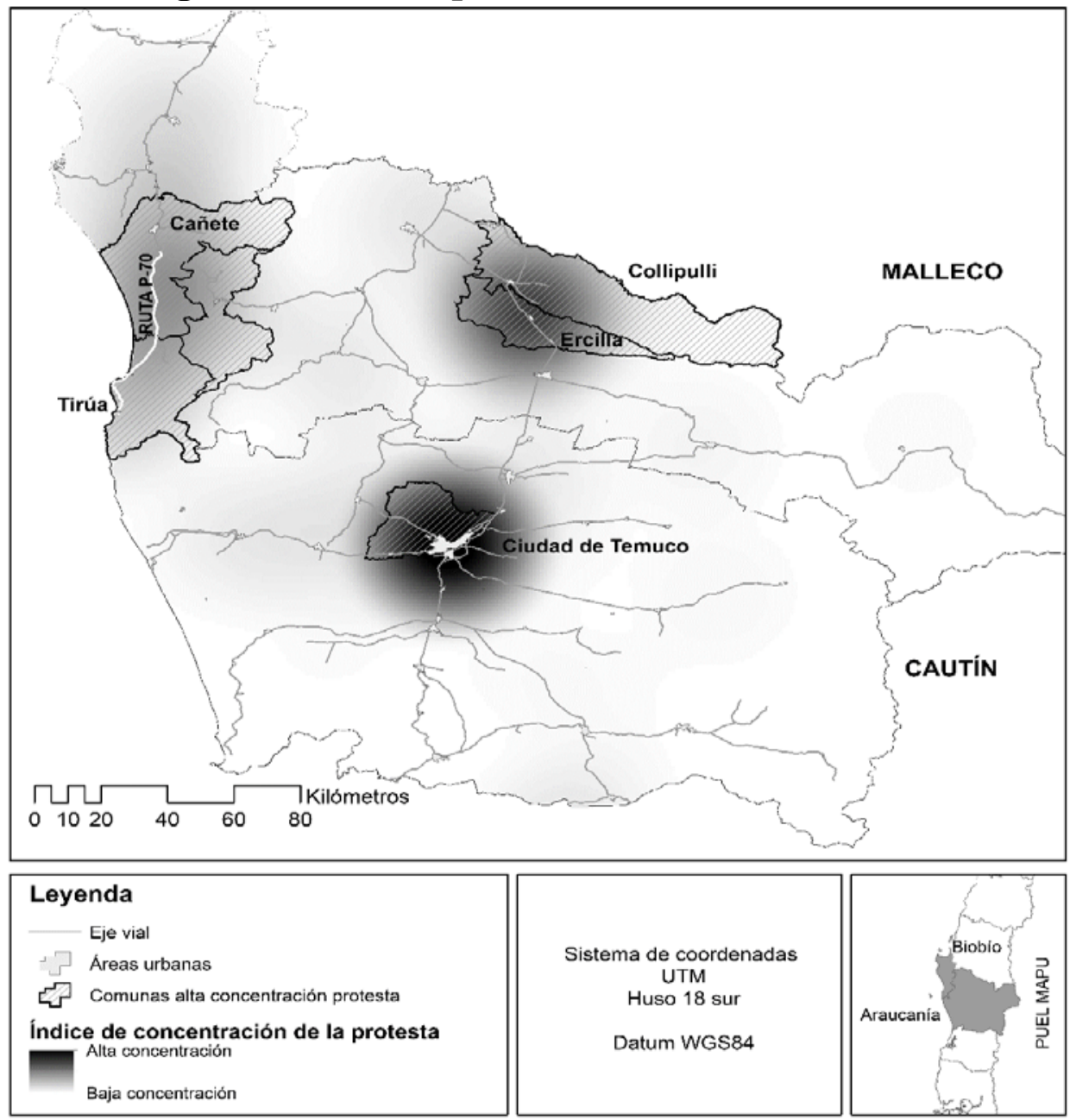

Fuente: Elaboración propia según medios de prensa estudiados 
Los territorios, se constituyen multidimensionalmente y se definen, en gran medida, por los actores que los habitan y las relaciones que establecen entre sí y con el entorno socioambiental. En la primera realidad socioterritorial del conflicto, aquella localizada en la provincia de Arauco, entre Cañete y Tirua, destaca la presencia de grandes empresas forestales frente a una población mapuche y chilena transversalmente empobrecida. Esto no sitúa el conflicto entre vecinos chilenos y mapuches, sino entre organizaciones que se oponen a los proyectos extractivos liderados desde Santiago por grandes consorcios empresariales. La confrontación directa en este territorio es principalmente entre organizaciones mapuche y las fuerzas policiales que defienden la propiedad privada. Esta realidad territorial es la que presenta la mayor proporción de repertorios de disrupción alta y que, principalmente, se asocian al conflicto forestal. Con todo, en este contexto destaca también la cifra más alta de ataques a vivienda en los últimos tres años, lo que da cuenta de cierto descontrol de la violencia, donde no se queman casas de grandes latifundistas (la gran propiedad aquí está principalmente en manos de grandes consorcios santiaguinos, no en familias locales), sino más bien se trataría, en gran medida, de conflictos entre comunidades y vecinos que se contraponen en sus disposiciones y relaciones con las empresas madereras.

Desde el año 2018, la conflictividad entre comunidades se ha acrecentado producto de la estrategia de cooptación y "buena vecindad" iniciada por Forestal Mininco en colaboración con el entonces Ministro de Desarrollo Social, Alfredo Moreno (ver Capítulo 6). Durante los gobiernos de Michelle Bachelet, sobre todo en el segundo, esta fue la zona más reprimida y la que concentró la mayor parte del gasto policial en la protección de las faenas forestales, bajo el slogan del combate contra al "robo de madera" (o, mejor dicho, la recuperación ambulatoria de los recursos del territorio por parte de las comunidades movilizadas). Finalmente, es importante destacar que esta zona, todavía en el año 2018, registra una importante presencia e 
influencia movimentista de las históricas organizaciones Identidad Lafquenche y la Coordinadora Arauco Malleco (CAM), pero también de comunidades o lof en resistencia que despliegan local y horizontalmente sus proyectos autonómicos.

La segunda realidad socioterritorial del conflicto, es la de Collipulli y Ercilla, en la Provincia de Malleco. Como se vio en sus repertorios de protesta, se trata del contexto de mayor diversidad, donde se conjugan acciones con distintos niveles de disrupción. Se está en presencia de un territorio con una matriz estructural del conflicto más diversa que la de Arauco, donde si bien existe una significativa presencia de industrias forestales, hay también presencia agrícola y ganadera, y en ciertas localidades las comunidades conviven con el latifundio, familias chilenas y europeas que concentran la propiedad de la tierra y sus recursos.

La confrontación en este territorio es directa y con altos niveles de violencia, pero también se canaliza institucionalmente. Es recordada la represión que sufrió en Malleco la Alianza Territorial Mapuche, y las comunidades en resistencia con un espectáculo policial desplegado entre los años 2010 y 2013 por el ex ministro Hinzpeter. Es esta zona la que sufrió los mayores embates represivos durante el primer Gobierno de Piñera y, coincidentemente, en el primer año de su segundo periodo -el año 2018- experimentó el trágico asesinato de Camilo Catrillanca en Temucuicui. La histórica Coordinadora Arauco Malleco, por cierto, mantiene influencia y presencia en este territorio, pero es menos notoria que la presencia de la Alianza Territorial Mapuche y las comunidades autónomas. Este es un territorio que, como se verá, presenta mixturas y complejidades, que las sitúan en medio término entre las características realidades de Arauco y Cautín. La tercera realidad socioterritorial del conflicto, es la de Cautín, principalmente Temuco y sus cercanías, como Padre Las Casas. Es esta zona la que concentra la mayor cantidad de protesta, principalmente de baja disrupción. Se registran dos grandes tipos de protesta: i) mayoritariamente, la protesta convencional, orientada a 
interpelar a las agencias estatales presentes en la capital, Temuco y ii) minoritariamente aquellas protestas orientadas a disputas postcoloniales, contra la élite chileno-europea -que representan el electorado de la derecha más radical y conservadora de la zona- y la diócesis católica, liderada generalmente por autoridades ligadas a esta misma élite. En este espacio geográfico, la Coordinadora Arauco Malleco aún conserva cierta influencia y presencia -aunque menor que en la década anterior- junto a diversas organizaciones de carácter más institucional como el Consejo de Todas Las Tierras, y otras más pequeñas, pero altamente disruptivas como Weichan Auka Mapu, conocida públicamente desde el año 2016. Durante el 2018, como se verá en la sección siguiente, la mayor parte de la protesta mapuche en este territorio se centró en dos casos emblemáticos: Iglesias y Luchsinger-Mackay. Estos dos casos explican, en gran parte, la particularidad del único territorio donde destaca el 2018 la huelga de hambre y la quema de iglesias como un repertorio de protesta.

\section{Dinámicas del conflicto: la protesta mapuche durante el 2018}

El Gráfico 5 muestra de qué manera se ha comportado la protesta mapuche durante todo el año 2018, según el nivel de disrupción en cada mes del año y la principal causa aludida a cada hecho en particular. La dinámica de la protesta muestra niveles relativamente estables durante el primer semestre del año, en el que el tema que más se repitió fue el caso Luchsinger-Mackay y, relacionado con ello, acciones en torno al machi Celestino Córdova, quien inició una huelga de hambre demandando visitar su rehue -espacio sagrado en la cosmovisión mapuche-. 


\section{Gráfico 5: Dinámica de la protesta según disrupción y causa aludida (frecuencia mensual)}

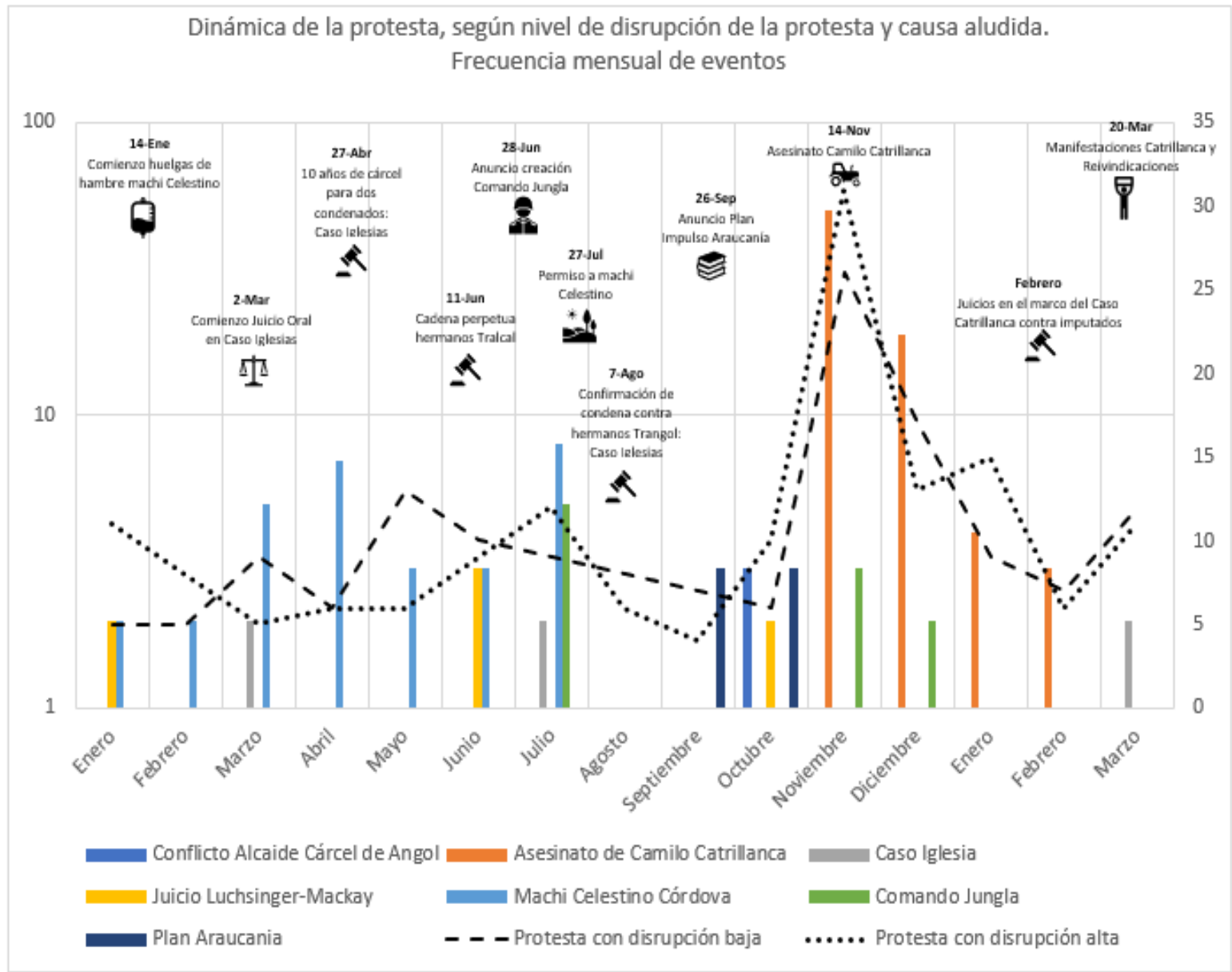

Fuente: Elaboración propia según medios de prensa estudiados

Ya en mitad del año 2018 existe un aumento en el total de protestas realizadas, inmediatamente después de dos condenas judiciales. El 27 de abril se sentencia a 10 años de presidio para dos de los procesados por el caso Iglesias y el 11 de junio se dictamina cadena perpetua 
contra los hermanos Tralcal en el marco del proceso judicial del caso Luchsinger-Mackay. De aquí en adelante, entre mayo y julio, se desataría un aumento significativo en la protesta mapuche: El mayor auge de la protesta en este periodo, y, en particular, de los repertorios altamente disruptivos, es en julio, luego de que el Gobierno anunciara la creación del Comando Jungla el 28 de junio del 2018. Esto da cuenta de la relación dinámica entre la protesta y la represión (ya sea policial o judicial). En este caso, el aumento cuantitativo de la protesta, pero también la radicalización de los repertorios son resultado interactivo de la arremetida represiva desarrollada desde el primer semestre del retorno de Piñera a La Moneda. En efecto, las causas de la protesta, ilustradas en el Gráfico 5, giran en torno a la huelga del machi Celestino Córdova y el Caso Iglesias, pero ahora se les suman la protesta en contra de la creación del Comando Jungla. En este contexto, estaríamos frente al despliegue de un ciclo de represión radicalizadora, que le da continuidad y profundidad a lo ya efectuado por Bachelet en su segundo periodo.

Desde agosto de 2018 existe una disminución en la protesta, luego del otorgamiento del permiso al machi Celestino Córdova para volver a su rehue. Esta situación también evidencia que las protestas no son impulsos ni simples arrebatos de los manifestantes, sino una respuesta directa a las acciones políticas emanadas desde el Gobierno central (Rojas Pedemonte y Miranda, 2016). Posteriormente, el anuncio del "Plan Impulso Araucanía", el 26 de septiembre, por parte del Gobierno de Sebastián Piñera, marca un hito que no deja indiferente a las organizaciones mapuche y desata - con el Comando Jungla ya desplegado en el territorio- un relativo incremento de la protesta, principalmente de los repertorios más disruptivos. No obstante, es, sin duda, el asesinato del comunero Camilo Catrillanca realizado por parte del Comando Jungla el 14 de noviembre, el hito más relevante del año y el que genera la mayor escalada de la protesta en el territorio mapuche, y como se describió en la introducción de este artículo, también en las grandes ciudades, incluida la capital chilena. Este hecho 
repercute fuertemente en el territorio estudiado, generando una oleada de protestas durante noviembre y diciembre. Éstas, en los últimos dos meses del año, están directamente relacionadas con este evento, como lo muestra el Gráfico 5, ya sea en referencia el asesinato de Catrillanca o al Comando Jungla, como iniciativa gubernamental desplegada desde los meses previos. Desde entonces se despliegan todo tipo de repertorios, pero aquellos más disruptivos son los que predominan. Ciertamente, se trata de un crudo ejemplo de la represión radicalizadora, desplegada por el Estado chileno contra el movimiento mapuche, de manera indiscriminada -no selectiva-, desproporcionada, fuera de protocolos y en escalada, como hace dos décadas evidencian los informes de los organismos internacionales (por ejemplo, los informes de la ONU de Stavenhagen, 2003; Anaya, 2009; y Emerson, 2014). Concretamente, corresponde a la gestión policial de un conflicto histórico y político, sobre la distribución del poder y el territorio.

A continuación se revisan en detalle los dos ciclos y auges de la protesta desatados durante el año 2018. El Gráfico 6 cubre los meses de mayo y julio, aquellos que darían cuenta de la primera interacción el movimiento mapuche y el nuevo Gobierno. Lo primero que se observa es una primera etapa (mayo-junio) donde la represión del movimiento se concentra en el ámbito judicial -la represión policial es permanente, pero el énfasis en estos meses es legal-, y la protesta se canaliza convencionalmente, con bajos niveles de disrupción. La sentencia de cadena perpetua a los hermanos Tralcal por el caso Luchsinger-Mackay el 11 de junio, sumada a la acumulación de agravios de ese primer semestre - como la condena a los hermanos Trangol (Iglesias), el Caso Huracán (en ese entonces aún en investigación) o la negación de permisos al machi Celestino para visitar su rehue derivaron a mitad de junio en un relativo aumento de los repertorios más disruptivos ${ }^{13}$. Con todo, el hito que viene a cambiar

${ }^{13}$ En el gráfico se muestra "violencia y contraviolencia", ésta da cuenta de aquellos repertorios altamente disruptivos como los ataques a maquinaria, vivienda, iglesias 
cuantitativa y cualitativamente la protesta es sin duda el anuncio de la creación del Comando Jungla el 29 de junio. Con diversas causas en juego -huelga del machi, Caso Iglesias, nuevos presos políticos con cadena perpetua-, luego de esta fuerte señal represiva por parte del Gobierno, se desata un aumento significativo de radicalidad de la protesta, incrementando el nivel de disrupción de los repertorios durante el mes de julio. Este análisis de los hechos de protesta a la luz del contexto político, permite identificar el carácter interactivo y cotidiano de la protesta en territorio mapuche.

En este periodo el caso Iglesias es de gran incidencia en la movilización mapuche. Si bien ocurrió en 2017, durante el año 2018 se concentraron varios hechos de protesta que tenían como contexto este caso, producto del procedimiento legal que se llevó a cabo durante este año. En el marco de esta coyuntura, se identificaron nueve protestas reseñadas por los distintos medios de comunicación estudiados, entre ellas, daño a maquinaria forestal en la comuna de Teodoro Schmidt, reivindicadas en este contexto; huelgas de hambre realizadas por los propios imputados; tres protestas en el marco de acciones legales durante el juicio, realizada por abogados defensores; acciones discursivas de los acusados, a través de declaraciones de inocencia; un ataque a un templo evangélico en Padre Las Casas; además de una manifestación realizada en Tribunales de Temuco el 7 de agosto, a propósito de la huelga de hambre realizada por los hermanos Trangol, quienes demandaban la anulación del juicio que sentenció a ambos imputados en el caso Iglesias.

Junto con ello, el caso Luchsinger-Mackay sigue siendo causa importante de las protestas durante este período (mayo-julio), pero también durante todo el 2018. En este sentido, se registraron varias acciones discursivas y comunicados defendiendo la inocencia de la Machi Francisca Linconao, sobre todo a principios de año y luego,

o colegios, enfrentamientos, entre otros. Se destaca así que la violencia política mapuche, no es un impulso aislado, sino una respuesta interactiva a las violencias hegemónicas en el territorio. 
durante junio, pidiendo apoyo y publicando videos sobre la inocencia de José y Luis Tralcal. Es, precisamente, desde este mes que comienzan a desarrollarse aquellas protestas más disruptivas: el 13 de junio, miembros de la CAM atacan un predio forestal pidiendo libertad de presos políticos en el caso Luchsinger; protestas y alteración del orden público mediante manifestaciones pacíficas y con diversos grados de violencia se desarrollaron el 5 de julio, el 3 de agosto y el 4 de octubre -entre otras- en las ciudades de Temuco y Padre Las Casas. Ligadas estrechamente con este caso, son las protestas realizadas por el machi Celestino Córdova, o bien, aquellas que han sintonizado con sus demandas. En esta línea, el 2018 fue testigo de 29 protestas con diversos grados de disrupción. Es a principios de año -14 de eneroque el machi Celestino comienza una huelga de hambre, reactivada en dos ocasiones más: el 31 de mayo y el 18 de julio, acciones que motivarán movilizaciones durante gran parte del año, exigiendo su liberación y el traslado a su rehue. De entre ellas, se identificaron 19 protestas con baja disrupción, en su mayoría manifestaciones y denuncias públicas contra quienes prohibían su traslado; además de siete protestas con mayor grado de disrupción, sobre todo ataques incendiarios reivindicando la liberación de presos políticos como el machi Celestino. Interactivamente, este ciclo termina, como fue posible ver en el gráfico 5, cuando permiten la visita del machi a su rehue, el 29 de julio del 2018. 
Gráfico 6: Dinámica de la protesta según disrupción y causa aludida (semanas mayo-julio)

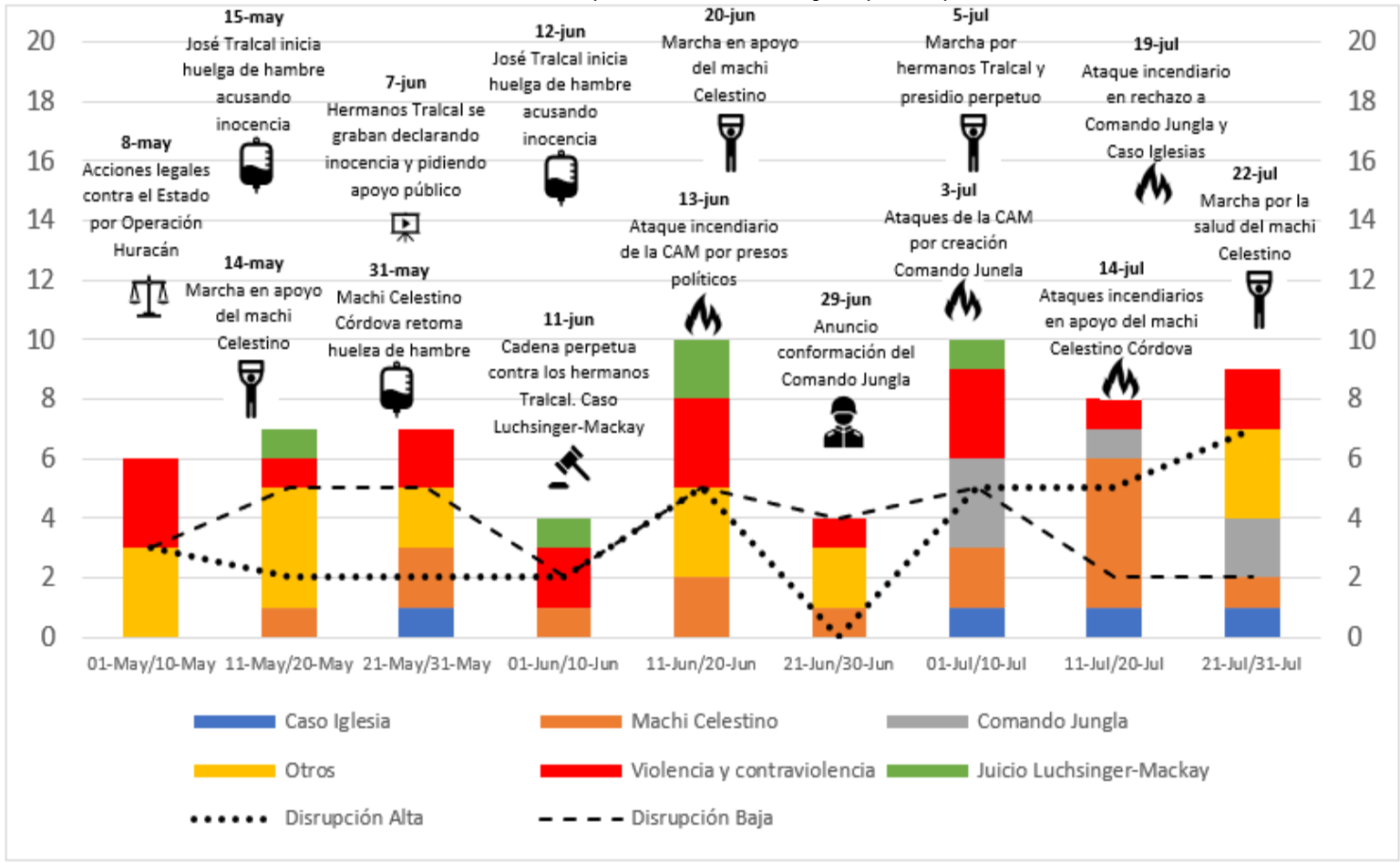

Fuente: Elaboración propia según medios de prensa estudiados

El gráfico 7 ilustra el ciclo de protesta desatada desde el asesinato de Catrillanca en Ercilla. Ciertamente, la masividad y los niveles de disrupción de la movilización en los primeros diez días posteriores al asesinato difícilmente son homologables a otro hito. La coyuntural desmovilización de los primeros días de noviembre contrasta ostensiblemente con el aumento explosivo de la protesta desde la misma noche del 14 de noviembre. Dada la indignación y la solidaridad provocadas por este asesinato, la movilización fue transversal y generalizada en los territorios. Tanto la protesta convencional, como la más radical se incrementaron exponencialmente durante estos primeros 10 días. A medida que los controversiales 
antecedentes del caso se fueron develando durante las últimas semanas de noviembre, la protesta se inclinó principalmente por los repertorios disruptivos. El mes siguiente el caso continuó en la agenda pública y las movilizaciones continuaron. Sin embargo, diciembre destacó por masivas marchas en las grandes ciudades (como las del martes 11 en Concepción ${ }^{14}$ y el viernes 21 en Temuco ${ }^{15}$ ), más que por la radicalidad de los repertorios desplegados.

\section{Gráfico 7: Dinámica de la protesta según disrupción y causa aludida (semanas nov.-dic.)}

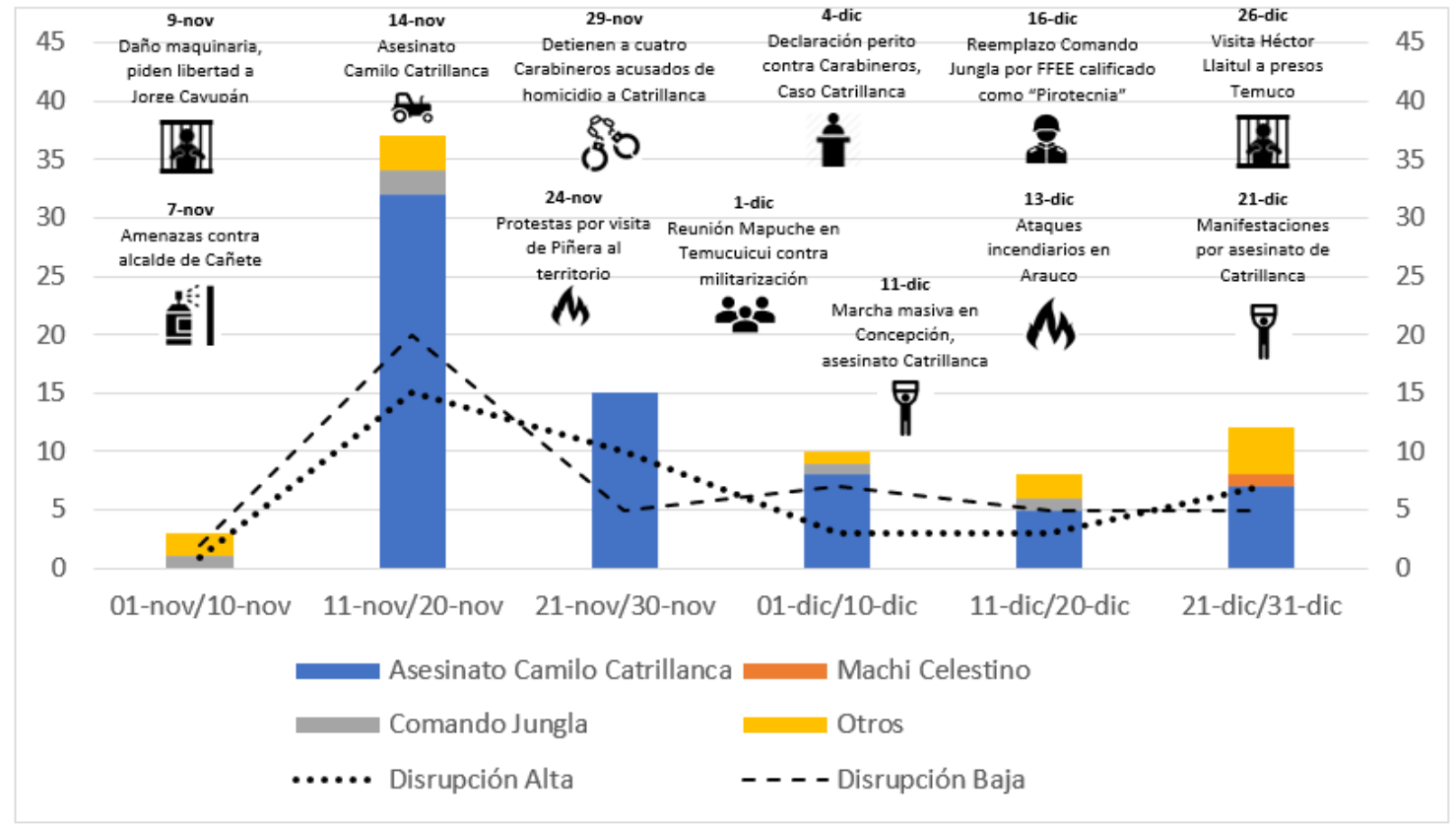

Fuente: Elaboración propia según medios de prensa estudiados

14https://www.biobiochile.cl/noticias/nacional/region-del-bio-

bio/2018/12/11/incidentes-en-concepcion-durante-marcha-por-homicidio-decatrillanca.shtml

15 http://lanacion.cl/2018/12/21/masiva-marcha-mapuche-en-temuco-convocadapor-padre-de-catrillanca/ 
Los hechos de protesta que se enmarcaron en el caso del asesinato de Camilo Catrillanca se concentraron, sobre todo, durante la segunda mitad del mes de noviembre y, luego, durante gran parte de diciembre del 2018. De un total de 69 hechos de protestas que provocó el asesinato de Camilo Catrillanca, 33 obedecen a una protesta con una baja disrupción, siendo 36 las protestas con una disrupción alta. Entre las primeras, se identificaron 11 protestas discursivas, sobre todo rechazando el asesinato de Catrillanca y reivindicando la lucha mapuche a través de manifestaciones y comunicados; una reunión de comunidades y organizaciones mapuche en Temucuicui; 7 acciones legales, presentadas principalmente por el INDH y abogados defensores; 3 comunicados públicos a modo de protesta contra Carabineros y la institucionalidad; y 11 manifestaciones y movilizaciones, sobre todo en las principales ciudades del territorio mapuche, como Temuco o Cañete.

Por otro lado, se identificaron 36 hechos de protesta con una alta disrupción: 2 ataques a colegios durante los primeros diez días después del asesinato del comunero; 2 ataques a iglesias los dos días inmediatamente después del fatídico hecho; 12 ataques a viviendas; 5 bloqueos de carretera; 8 ataques incendiarios a maquinaria forestal y camiones de otras empresas; 3 emboscadas; un enfrentamiento directo con Carabineros en territorio; una acción de recuperación de predios forestales en homenaje al fallecido comunero; y 2 tomas, una en la municipalidad de Teodoro Schmidt y otra realizada por estudiantes en un liceo de Ercilla. Las protestas por el asesinato de Camilo Catrillanca exceden las fronteras del Wallmapu, y convocaron transversalmente a diversos actores de la sociedad civil chilena. Su alcance e influencia son ingentes a lo largo del territorio chileno, y su repercusión resulta evidente en la "Primavera Chilena" de octubre de 2019, donde se enarboló la wenufoye -bandera del movimiento mapuche- en lo más alto de Plaza Italia en Santiago y se reconoció como síntesis simbólica de todas las luchas sociales. No obstante, la continuidad de estos ciclos de 
movilización deberá ser estudiada en el próximo anuario sobre el año 2019.

\section{Conclusiones y reflexiones}

En última instancia, este artículo da cuenta de la vitalidad y dinamismo del movimiento mapuche. Destaca la diversidad de su movilización y repertorios, como interacción permanente con las políticas de supresión de la protesta. La mirada cronológica de los eventos y el análisis contextual permitió describir el curso del conflicto como un proceso dinámico en permanente construcción. En este sentido, la protesta mapuche y sus modalidades de lucha no solo son parte de un ideario o cultura política y movimentista, sino principalmente son producto de la relación histórica con el Estado y de la cotidiana confrontación con sus fuerzas policiales, agencias judiciales y políticas. El año 2018, el primer año del retorno de Sebastián Piñera a la Presidencia de Chile, seguramente será recordado como una fuerte arremetida represiva en el territorio, primero con un énfasis judicial y luego policial, con el asesinato de Camilo Catrillanca como su triste ejemplo. No obstante, también será recordado por la vigencia de la causa mapuche, por su permanente actividad movimentista y por su resonancia política en todo el territorio chileno.

Este estudio esbozó la presencia de diversas realidades territoriales del conflicto, con dinámicas, actores y repertorios particulares. Así mismo, describió comparativamente la protesta en las tres provincias estudiadas, con el objetivo de poner en perspectiva y contexto los hechos registrados. En este sentido, se pudo observar las diferentes maneras en que la causa mapuche y el movimiento, de manera general, logra desplegar una serie de acciones en distintas partes del territorio, identificando espacios particulares, desde el punto de vista estratégico, reconociéndose parte de un territorio y un espacio geográfico que ha sido construido social e históricamente por comunidades Mapuche desde hace más de 500 años. Por ello, es importante recalcar las fuertes diferencias que pueden existir entre espacios urbanos y rurales: 
los primeros, configurados como territorios en los que es posible desplegar estrategias de baja disrupción, pero que permiten visibilizar fácilmente las demandas del Pueblo Mapuche; los segundos, territorios protagonizados por la fuerte confrontación entre comunidades mapuche y empresas extractivas (sobre todo en Arauco y Malleco) quienes, amparadas por fuerzas policiales del Estado, protagonizan un conflicto caracterizado por los repertorios de protesta se han radicales.

De esta forma, la protesta no se trata de cifras ni menos de meras noticias, sino de interacciones entre instituciones, sujetos colectivos y personas concretas en el territorio habitado, respondiendo a procesos históricamente construidos. Las protestas durante el 2018, ciertamente, no evidenciaron una agenda propia, sino más bien fueron expresión del escenario de confrontación en que se desplegaron. Las protestas se vincularon principalmente a tres hitos y procesos: desarrollo del juicio de hermanos Tralcal en el caso Luchsinger-Mackay; las repercusiones judiciales del caso Iglesias; y el asesinato de Camilo Catrillanca. Con todo, la relevancia de estas coyunturas no permite obviar la raíz estructural de la lucha mapuche ni menos las demandas históricas que le dan continuidad y sentido a la movilización.

Este capítulo, permite situar la protesta mapuche durante el 2018, pero necesita ser siempre complementado con el análisis de ciclos de protestas anteriores y posteriores. Darle continuidad a este análisis cronológicamente permitirá identificar cursos, relaciones causales y contextos diversos en los que la movilización va configurándose, modificándose y renovándose. Asimismo, este conflicto requiere ser entendido desde múltiples aristas, por lo cual los siguientes capítulos que acompañan esta discusión sobre la protesta mapuche podrán ayudar a construir un mejor panorama para entender un año cargado de hitos y dinámicas de este territorio en conflicto. Con todo, el análisis de detallado y cotidiano del conflicto que ofrece este Anuario, y este artículo e particular, es fundamental para entender el conflicto 
como un proceso en curso, no predeterminado, sino más bien situado histórica y socioterritorialmente.

\section{Bibliografía}

Amolef, F. (2005): "La alteridad en el discurso mediático: los mapuche y la prensa chilena", Boletín IFP, 2 (6),

Anaya, S. J. (2009). Principios internacionales aplicables a la consulta en relación con la reforma constitucional en materia de derechos de los pueblos indígenas en Chile. Recuperado de: www.ohchr.org/english/issues/indigenous/rapporteur/countr yreports.htm>

Emerson, B. (2014). Report of the Special Rapporteur on the promotion and protection of human rights and fundamental freedoms while countering terrorism. Recuperado de: http://www.politicaspublicas.net/panel/images/stories/docs/ 2014-report-chile-ben-emmerson-a-hrc-25-59-add-2-auv.pdf

Labrín, J.M. (2011): Análisis de cobertura y tratamiento de conflictos indígenas 2010-2011, Universidad de Chile/Unesco, Santiago de Chile

Rojas Pedemonte, N., \& Miranda, O. (2015). Dinámica sociopolítica del conflicto y la violencia en territorio mapuche. Particularidades históricas de un nuevo ciclo en las relaciones contenciosas. Revista de Sociología (30), 33-69.

Rojas Pedemonte, N. \& Lobos, C. (2016). Violencia estructural y exclusión del Pueblo Mapuche: estadísticas multidimensionales de un territorio en conflicto. Documento de trabajo recuperado de:https://odsal.oducal.com/documentos/violencia $\% 20$ estruct ural $\% 20 y \% 20$ exclusion $\% 20$ del $\% 20$ pueblo $\% 20$ mapuche_14997 13606.pdf

Stavenhagen, R. (2003). Informe del Relator Especial sobre la situación de los derechos humanos y libertades fundamentales de los indígenas. E/CN, 4, 90. 


\section{Anexos}

\section{Cronología de la protesta mapuche en 2018}

\begin{tabular}{|c|c|c|}
\hline Fecha & Acontecimiento & Descripción \\
\hline $\begin{array}{l}14 \text { de } \\
\text { enero de } \\
2018\end{array}$ & $\begin{array}{l}\text { Comienzo huelga de } \\
\text { hambre machi Celestino } \\
\text { Córdova }\end{array}$ & $\begin{array}{l}\text { El machi Celestino Córdova decide } \\
\text { iniciar una huelga de hambre líquida } \\
\text { debido a la nula respuesta por parte del } \\
\text { Estado de Chile a sus solicitudes, } \\
\text { presentadas por el conducto regular, } \\
\text { solicitando } 48 \text { horas de salida a su rehue. }\end{array}$ \\
\hline $\begin{array}{l}2 \text { de marzo } \\
\text { de } 2018\end{array}$ & $\begin{array}{l}\text { Comienzo juicio oral en } \\
\text { caso Iglesias }\end{array}$ & $\begin{array}{l}\text { Comienza juicio que acusa a cuatro } \\
\text { comuneros mapuche por la quema de un } \\
\text { templo evangélico en Padre Las Casas. La } \\
\text { defensa recalcó que no existe ninguna } \\
\text { participación de los imputados en el } \\
\text { hecho }\end{array}$ \\
\hline $\begin{array}{l}27 \text { de abril } \\
\text { de } 2018\end{array}$ & $\begin{array}{l}\text { Condena de } 10 \text { años de } \\
\text { cárcel para dos } \\
\text { condenados en el caso } \\
\text { Iglesias }\end{array}$ & $\begin{array}{l}\text { Se presenta querella en contra de los } \\
\text { miembros de Carabineros de Chile } \\
\text { involucrados en el montaje denominado } \\
\text { "Operación Huracán", y en contra todos } \\
\text { quienes resulten responsables por los } \\
\text { hechos. }\end{array}$ \\
\hline
\end{tabular}




\begin{tabular}{|c|c|c|}
\hline $\begin{array}{l}8 \text { de mayo } \\
\text { de } 2018\end{array}$ & $\begin{array}{l}\text { Acciones legales contra } \\
\text { el Estado por Operación } \\
\text { Huracán }\end{array}$ & $\begin{array}{l}\text { La organización Consejo de Todas las } \\
\text { Tierras anunció acciones legales contra el } \\
\text { Estado por "Operación Huracán," el } \\
\text { sistema institucional de los carabineros } \\
\text { para interceptar comunicaciones y espiar } \\
\text { en acciones de comunidades mapuche. }\end{array}$ \\
\hline $\begin{array}{l}14 \text { de mayo } \\
\text { de } 2018\end{array}$ & $\begin{array}{l}\text { Se realiza masiva marcha } \\
\text { en apoyo del machi } \\
\text { Celestino Córdova }\end{array}$ & $\begin{array}{l}\text { Se realiza nueva marcha en favor de } \\
\text { Celestino Córdova, reuniendo } 200 \\
\text { personas manifestándose pacíficamente } \\
\text { en Nueva Imperial. El intendente Luis } \\
\text { Mayol negó que existan compromisos o } \\
\text { negociaciones para que Córdova visite su } \\
\text { rebue. }\end{array}$ \\
\hline $\begin{array}{l}15 \text { de mayo } \\
\text { de } 2018\end{array}$ & $\begin{array}{l}\text { José Tralcal inicia huelga } \\
\text { de hambre acusando } \\
\text { inocencia }\end{array}$ & $\begin{array}{l}\text { José Tralcal, uno de los imputados por el } \\
\text { caso Luchsinger-MacKay, empezó una } \\
\text { huelga de hambre rechazando la } \\
\text { aplicación de la Ley Antiterrorista. }\end{array}$ \\
\hline $\begin{array}{l}31 \text { de mayo } \\
\text { de } 2018\end{array}$ & $\begin{array}{l}\text { Machi Celestino } \\
\text { Córdova retoma huelga } \\
\text { de hambre }\end{array}$ & $\begin{array}{l}\text { El machi Celestino retoma huelga de } \\
\text { hambre en protesta por la nueva negativa } \\
\text { de Gendarmería a concederle un permiso } \\
\text { de } 48 \text { horas para renovar su rehue. }\end{array}$ \\
\hline $\begin{array}{l}7 \text { de junio } \\
\text { de } 2018\end{array}$ & $\begin{array}{l}\text { Hermanos Tralcal se } \\
\text { graban declarando } \\
\text { inocencia y pidiendo } \\
\text { apoyo }\end{array}$ & $\begin{array}{l}\text { Los hermanos José y Luis Tralcal } \\
\text { publicaron videos declarando inocencia } \\
\text { en el caso Luchsinger-MacKay, pidiendo } \\
\text { apoyo público y revisión de la Ley } \\
\text { Antiterrorista. }\end{array}$ \\
\hline
\end{tabular}




\begin{tabular}{|c|c|c|}
\hline $\begin{array}{l}11 \text { de junio } \\
\text { de } 2019\end{array}$ & $\begin{array}{l}\text { Sentencia de cadena } \\
\text { perpetua por } \\
\text { Luchsinger-Mackay }\end{array}$ & $\begin{array}{l}\text { Sentencia de cadena perpetua a los } \\
\text { hermanos Tralcal por el caso Luchsinger- } \\
\text { Mackay. }\end{array}$ \\
\hline $\begin{array}{l}12 \text { de junio } \\
\text { de } 2018\end{array}$ & $\begin{array}{l}\text { José Tralcal inicia huelga } \\
\text { de hambre acusando } \\
\text { inocencia }\end{array}$ & $\begin{array}{l}\text { José Tralcal declaró una huelga de } \\
\text { hambre indefinida contra su pena en el } \\
\text { caso Luchsinger-MacKay, asegurando } \\
\text { que fue condenado de manera injusta, } \\
\text { con un relato sacado a través de torturas. }\end{array}$ \\
\hline $\begin{array}{l}13 \text { de junio } \\
\text { de } 2018\end{array}$ & $\begin{array}{l}\text { Cadena perpetua a } \\
\text { hermanos Tralcal }\end{array}$ & $\begin{array}{l}\text { Tribunal Oral en lo Penal de Temuco } \\
\text { declara medida de presidio perpetuo por } \\
\text { el delito de incendio con resultado de } \\
\text { muerte en carácter terrorista en el caso } \\
\text { Luchsinger Mackay para dos de los } \\
\text { condenados. El tercero fue sentenciado a } \\
\text { cinco años de presidio }\end{array}$ \\
\hline $\begin{array}{l}13 \text { de junio } \\
\text { de } 2018\end{array}$ & $\begin{array}{l}\text { Ataque incendiario de la } \\
\text { CAM por presos } \\
\text { políticos }\end{array}$ & $\begin{array}{l}\text { Miembros de CAM quemaron una cabina } \\
\text { en un predio forestal, destruyendo una } \\
\text { máquina de construcción. Dejaron una } \\
\text { carta advocando por la libertad de presos } \\
\text { políticos. }\end{array}$ \\
\hline $\begin{array}{l}20 \text { de junio } \\
\text { de } 2018\end{array}$ & $\begin{array}{l}\text { Masiva marcha en apoyo } \\
\text { del machi Celestino } \\
\text { Córdova }\end{array}$ & $\begin{array}{l}\text { Comunidades mapuche se movilizaron } \\
\text { en el centro de Temuco para exigir la } \\
\text { salida de } 48 \text { horas de Córdova para } \\
\text { cumplir con su ritual espiritual }\end{array}$ \\
\hline $\begin{array}{l}28 \text { de junio } \\
\text { de } 2018\end{array}$ & $\begin{array}{l}\text { Sebastián Piñera presenta } \\
\text { a Grupo Especial de } \\
\text { Carabineros para el } \\
\text { combate eficaz del } \\
\text { terrorismo en la }\end{array}$ & $\begin{array}{l}\text { El presidente presenta a las autoridades y } \\
\text { a la prensa un contingente especial del } \\
\text { Grupo de Operaciones Policiales } \\
\text { Especiales (GOPE) de Carabineros, } \\
\text { formados en Colombia y Estados }\end{array}$ \\
\hline
\end{tabular}




\begin{tabular}{|l|l|l|}
\hline & $\begin{array}{l}\text { Araucanía. Comando } \\
\text { Jungla }\end{array}$ & $\begin{array}{l}\text { Unidos, para operar en zonas donde "se } \\
\text { producen la mayor cantidad de atentados } \\
\text { incendiarios". Dicho grupo fue } \\
\text { denominado Comando Jungla. }\end{array}$ \\
\hline $\begin{array}{l}3 \text { de julio } \\
\text { de } 2018\end{array}$ & $\begin{array}{l}\text { Ataques de la CAM por } \\
\text { creación de Comando } \\
\text { Jungla }\end{array}$ & $\begin{array}{l}\text { CAM se adjudicó tres ataques } \\
\text { incendiarios en los sectores rurales de } \\
\text { Lumaco y Carahue. La organización } \\
\text { criticó las recientes medidas anunciadas } \\
\text { por el gobierno como la creación del } \\
\text { Comando Jungla. }\end{array}$ \\
\hline $\begin{array}{l}5 \text { de julio } \\
\text { de } 2018\end{array}$ & $\begin{array}{l}\text { Marcha en apoyo a } \\
\text { hermanos Tralcal y su } \\
\text { presidio perpetuo }\end{array}$ & $\begin{array}{l}\text { Cerca de 100 personas marcharon en } \\
\text { apoyo de los hermanos Tralcal en el } \\
\text { centro de Temuco, luego de que } \\
\text { recibieran presidio perpetuo por el caso } \\
\text { Luchsinger Mackay. }\end{array}$ \\
\hline $\begin{array}{l}14 \text { de julio } \\
\text { de } 2018\end{array}$ & $\begin{array}{l}\text { Ataques incendiarios en } \\
\text { apoyo del machi } \\
\text { Celestino Córdova }\end{array}$ & $\begin{array}{l}\text { Ataque incendiario en Lumaco, a 150 } \\
\text { metros del plano urbano, destruyó una } \\
\text { casa que estaba deshabitada. En el lugar } \\
\text { se encontró un lienzo que hace alusión a } \\
\text { la situación que vive el machi Celestino } \\
\text { Córdova. }\end{array}$ \\
\hline de 2018 & $\begin{array}{l}\text { Ataque incendiario en } \\
\text { rechazo a Comando } \\
\text { Jungla y caso Iglesias }\end{array}$ & $\begin{array}{l}\text { Desconocidos quemaron maquinaria } \\
\text { forestal en la localidad de Barros Arana, } \\
\text { comuna de Teodoro Schmidt. En el lugar } \\
\text { se encontraron panfletos alusivos a } \\
\text { presos políticos del Caso Iglesias. }\end{array}$ \\
\hline
\end{tabular}




\begin{tabular}{|c|c|c|}
\hline $\begin{array}{l}27 \text { de julio } \\
\text { de } 2018\end{array}$ & $\begin{array}{l}\text { Otorgamiento del } \\
\text { permiso al machi } \\
\text { Celestino Córdova para } \\
\text { visitar su rehue }\end{array}$ & $\begin{array}{l}\text { El machi es autorizado por Gendarmería, } \\
\text { tras decisión del comité técnico. La } \\
\text { información fue ratificada por el ministro } \\
\text { de Justicia y Derechos Humanos, Hernán } \\
\text { Larraín, en conferencia de prensa }\end{array}$ \\
\hline $\begin{array}{l}7 \text { de agosto } \\
\text { de } 2018\end{array}$ & $\begin{array}{l}\text { Confirmación de } \\
\text { condena contra } \\
\text { hermanos Trangol en el } \\
\text { caso Iglesias }\end{array}$ & $\begin{array}{l}\text { Corte de Apelaciones confirmó condena } \\
\text { contra hermanos Trangol por caso } \\
\text { Iglesia. De esta forma, la sentencia en } \\
\text { contra de Benito y Pablo Trangol por el } \\
\text { ataque incendiario quedó ejecutada y } \\
\text { deberá ser cumplida a la brevedad en la } \\
\text { Cárcel de Temuco }\end{array}$ \\
\hline $\begin{array}{l}26 \text { de } \\
\text { septiembre } \\
\text { de } 2018\end{array}$ & $\begin{array}{l}\text { Anuncio del Plan } \\
\text { Impulso Araucanía }\end{array}$ & $\begin{array}{l}\text { El presidente Sebastián Piñera, encabezó } \\
\text { la ceremonia donde se presentó el Plan } \\
\text { Impulso Araucanía. Reconocimiento de } \\
\text { los pueblos originarios, regularización de } \\
\text { tierras y ley de cuotas fueron los } \\
\text { principales anuncios. La instancia se } \\
\text { desarrolló a los pies del cerro Nielol, en } \\
\text { el pabellón El Amor de Chile. }\end{array}$ \\
\hline $\begin{array}{l}10 \text { de } \\
\text { octubre de } \\
2018\end{array}$ & $\begin{array}{l}\text { Dictan condena de } 18 \\
\text { años a hermanos Tralcal } \\
\text { por caso Luchsinger } \\
\text { Mackay pero quitan } \\
\text { carácter terrorista }\end{array}$ & $\begin{array}{l}\text { La Sala Penal de la Corte Suprema } \\
\text { confirmó la sentencia condenatoria del } \\
\text { Tribunal Oral de lo Penal de Temuco, } \\
\text { modificando únicamente la calificación } \\
\text { jurídica del delito y la pena aplicable, } \\
\text { condenando a los hermanos Tralcal a } 18 \\
\text { años de cárcel por el delito de incendio } \\
\text { común con resultado de muerte y } 5 \text { años } \\
\text { de para José Peralino Huinca. }\end{array}$ \\
\hline
\end{tabular}




\begin{tabular}{|l|l|l|}
\hline $\begin{array}{l}\text { 9 de } \\
\text { noviembre } \\
\text { de } 2018\end{array}$ & $\begin{array}{l}\text { Daño a maquinaria y } \\
\text { ataque incendiario } \\
\text { pidiendo libertad de } \\
\text { Jorge Cayupán }\end{array}$ & $\begin{array}{l}\text { Maquinaria amaneció quemada en } \\
\text { Lautaro. En el lugar se encontraron } \\
\text { panfletos que pide libertad de Jorge } \\
\text { Cayupán, comunero baleado por el } \\
\text { Comando Jungla 25 días antes del } \\
\text { asesinato de Camilo Catrillanca }\end{array}$ \\
\hline $\begin{array}{l}14 \text { de } \\
\text { noviembre, } \\
2018\end{array}$ & $\begin{array}{l}\text { Asesinato de Camilo } \\
\text { frustranca y homicidio } \\
\text { de iniciales M.A.P.C. }\end{array}$ & $\begin{array}{l}\text { El joven mapuche Camilo Catrillanca es } \\
\text { asesinado por miembros del llamado } \\
\text { "Comando Jungla" en la comunidad de } \\
\text { Temucuicui, Ercilla. Conjuntamente, } \\
\text { proceden a detener y golpear al } \\
\text { adolescente M.A.P.C. }\end{array}$ \\
\hline $\begin{array}{l}24 \text { de } \\
\text { noviembre } \\
\text { de } 2018\end{array}$ & $\begin{array}{l}\text { Protestas por visita de } \\
\text { Piñera al territorio }\end{array}$ & $\begin{array}{l}\text { Manifestantes cortan el tránsito en centro } \\
\text { de Temuco en rechazo a la visita de } \\
\text { Piñera en la zona. Servicentro en Ercilla } \\
\text { fue atacado por desconocidos durante la } \\
\text { noche del viernes. El evento se enmarca } \\
\text { en una jornada que estuvo marcada por la } \\
\text { visita de Piñera. Entre otros. }\end{array}$ \\
\hline $\begin{array}{l}1 \text { de } \\
\text { diciembre } \\
\text { de } 2018\end{array}$ & $\begin{array}{l}\text { Reunión comunidades } \\
\text { mapuche en Temucuicui } \\
\text { contra la militarización }\end{array}$ & $\begin{array}{l}\text { Líderes mapuche se reúnen en } \\
\text { Temucuicui y se registra un incidente } \\
\text { aislado en la zona. La cita busca fijar } \\
\text { posturas por parte de las comunidades. }\end{array}$ \\
\hline $\begin{array}{l}\text { 29 de } \\
\text { de } 2018\end{array}$ & $\begin{array}{l}\text { Detienbren a cuatro } \\
\text { carabineros acusados de } \\
\text { homicidio a Catrillanca }\end{array}$ & $\begin{array}{l}\text { Detienen a los cuatro carabineros } \\
\text { acusados del homicidio de Camilo } \\
\text { Catrillanca. Este viernes en Collipulli se } \\
\text { realizará la audiencia de control de la } \\
\text { detención de los carabineros. }\end{array}$ \\
\hline
\end{tabular}




\begin{tabular}{|c|c|c|}
\hline $\begin{array}{l}4 \text { de } \\
\text { diciembre } \\
\text { de } 2018\end{array}$ & $\begin{array}{l}\text { Declaración perito } \\
\text { contra Carabineros, en el } \\
\text { marco del Caso } \\
\text { Catrillanca }\end{array}$ & $\begin{array}{l}\text { Perito de la PDI declaró que carabinero } \\
\text { que mató a Catrillanca disparó siete tiros, } \\
\text { siendo uno de esos el que mató al } \\
\text { comunero el } 14 \text { de noviembre en Ercilla }\end{array}$ \\
\hline $\begin{array}{l}11 \text { de } \\
\text { diciembre } \\
\text { de } 2018\end{array}$ & $\begin{array}{l}\text { Marcha masiva en } \\
\text { Concepción por muerte } \\
\text { de Catrillanca }\end{array}$ & $\begin{array}{l}\text { Marcha no autorizada por la muerte de } \\
\text { Camilo Catrillanca se efectuó en } \\
\text { Concepción, que fue interceptada por } \\
\text { FF.EE. Tres personas fueron detenidas } \\
\text { durante los incidentes. }\end{array}$ \\
\hline $\begin{array}{l}13 \text { de } \\
\text { diciembre } \\
\text { de } 2018\end{array}$ & $\begin{array}{l}\text { Ataques incendiarios en } \\
\text { Arauco }\end{array}$ & $\begin{array}{l}\text { Residente acusa ataque incendiario } \\
\text { siniestro que consumió su casa en el } \\
\text { sector de Lleu Lleu, El incendio afectó a } \\
\text { una vivienda y una bodega en la ruta P- } \\
70 . .\end{array}$ \\
\hline $\begin{array}{l}16 \text { de } \\
\text { diciembre } \\
\text { de } 2018\end{array}$ & $\begin{array}{l}\text { Reemplazo Comando } \\
\text { Jungla por FF.EE., } \\
\text { calificado como } \\
\text { "Pirotecnia" }\end{array}$ & $\begin{array}{l}\text { Alcalde de Tirúa califica como } \\
\text { "pirotecnia" reemplazo del Comando } \\
\text { Jungla por personal de FFEE. Milabur } \\
\text { advierte que mantener la militarización y } \\
\text { la represión no es un camino para la } \\
\text { solución. Insistió en que la dirección } \\
\text { debe ser el diálogo }\end{array}$ \\
\hline $\begin{array}{l}21 \text { de } \\
\text { diciembre } \\
\text { de } 2018\end{array}$ & $\begin{array}{l}\text { Masivas manifestaciones } \\
\text { por asesinato de } \\
\text { Catrillanca }\end{array}$ & $\begin{array}{l}\text { Cerca de } 600 \text { personas participan en } \\
\text { marcha convocada por el padre de } \\
\text { Camilo Catrillanca en Temuco, luego de } \\
\text { que dieran a conocer los crudos videos } \\
\text { del operativo policial }\end{array}$ \\
\hline
\end{tabular}




\begin{tabular}{|l|l|l|}
\hline $\begin{array}{l}26 \text { de } \\
\text { diciembre } \\
\text { de } 2018\end{array}$ & $\begin{array}{l}\text { Visita de Héctor Llaitul a } \\
\text { presos en Temuco }\end{array}$ & $\begin{array}{l}\text { Héctor Llaitul visitó a presos mapuche en } \\
\text { la Cárcel de Temuco. Uno de los } \\
\text { condenados con quien se habría reunido } \\
\text { sería Facundo Jones Huala, quien fue } \\
\text { sentenciado por su participación en } \\
\text { delitos de incendio y tenencia ilegal de } \\
\text { armas; y el machi Celestino Córdova }\end{array}$ \\
\hline
\end{tabular}

